\title{
The impact of patient education on the quality of inpatient bowel preparation for colonoscopy
}

\author{
Greg Rosenfeld MD ${ }^{1}$, Darin Krygier MD FRCPC ${ }^{1}$, Robert A Enns MD FRCPC ${ }^{2}$, \\ Janakie Singham MD FRCPC ${ }^{1}$, Holly Wiesinger MD FRCPC ${ }^{1}$, Brian Bressler MD FRCPC ${ }^{2}$
}

G Rosenfeld, D Krygier, RA Enns, J Singham, H Wiesinger, B Bressler. The impact of patient education on the quality of inpatient bowel preparation for colonoscopy. Can J Gastroenterol 2010;24(9):543-546.

BACKGROUND: For patients requiring colonoscopy while admitted to hospital, achieving adequate cleansing of the colon is often difficult. OBJECTIVES: To assess the impact of patient education, in the form of both counselling and written instructions, on bowel cleanliness at colonoscopy.

METHODS: A total of 38 inpatients at a tertiary care hospital in Vancouver, British Columbia, who were referred to the gastroenterology service for colonoscopy were enrolled in the present study. Sixteen patients were randomly assigned to the intervention group, while 22 patients comprised the control group. Both groups received a clear liquid diet and $4 \mathrm{~L}$ of a commercially available bowel preparation. The intervention group also received a brief counselling session and written instructions outlining the methods and rationale for bowel preparation before colonoscopy. Bowel cleanliness was assessed by the endoscopist using a five-point rating scale.

RESULTS: The two groups were similar with respect to demographics, the indication for colonoscopy and findings at colonoscopy. The median bowel cleanliness scores in the control group and the enhanced-instruction group were 3.0 and 2.0, respectively $(\mathrm{P}=0.001)$. CONCLUSION: Patient counselling and written instructions are inexpensive, safe and simple interventions. Such interventions are an effective means of optimizing colonoscopy preparation in the inpatient setting.

Key Words: Bowel preparation; Colonoscopy; Inpatients

A $n$ essential first step to efficacious colonoscopy is adequate bowel cleansing. Successful visualization of the colon and detection of pathological lesions is dependent on adequate colon preparation $(1,2)$. Up to $23 \%$ of all colonoscopies are associated with suboptimal bowel preparation (3). The net result of poor preparation is lower cecal intubation rates, longer procedure times, decreased polyp detection and increased costs (4). The proportion of inadequately prepared patients is higher in hospitalized patients (5), resulting in a greater number of repeat procedures and, consequently, increased risk, cost and discomfort to the patient.

Predictors of the adequacy of bowel preparation include the cleansing agent, the protocol used, the consumption of water up to the time of colonoscopy, and the length of time between initiation of preparation and the colonoscopy (5). There are also patient-related factors such as colonic pathology, the presence of comorbidities, the indication for colonoscopy and the
Les répercussions de l'éducation des patients sur la qualité de la préparation intestinale à la coloscopie chez les patients hospitalisés

HISTORIQUE : Chez les patients qui doivent subir une coloscopie en cours d'hospitalisation, il est souvent difficile d'obtenir à un nettoyage adéquat du côlon.

OBJECTIFS : Évaluer les répercussions de l'éducation des patients, sous forme de conseils et de directives écrites, sur la propreté intestinale lors de la coloscopie.

MÉTHODOLOGIE : Au total, 38 patients hospitalisés dans un hôpital de soins tertiaires de Vancouver, en Colombie-Britannique, aiguillés au service de gastroentérologie afin de subir une coloscopie, ont participé à la présente étude. Seize patients ont été placés aléatoirement dans le groupe d'intervention, tandis que 22 patients composaient le groupe témoin. Les deux groupes ont reçu une diète liquide claire et 4 litres d'une préparation intestinale commerciale. Le groupe d'intervention a également eu droit à une brève séance de conseils et à des directives écrites soulignant les méthodes pour utiliser la préparation intestinale avant la coloscopie et la raison de le faire. L'endoscopiste a évalué la propreté intestinale au moyen d'une échelle de cinq points.

RÉSULTATS : Les deux groupes avaient une démographie, une indication de coloscopie et des observations à la coloscopie similaires. Les indices de propreté intestinale médiane dans le groupe témoin et le groupe d'intervention s'élevaient à 3,0 et à 2,0, respectivement $(\mathrm{P}=0,001)$.

CONCLUSION : Les conseils et les directives écrites aux patients sont des interventions simples, peu coûteuses et sécuritaires. Ils constituent un moyen efficace d'optimiser la préparation à la coloscopie chez les patients hospitalisés.

ability to understand and follow instructions appropriately. Successful completion of the preparatory procedure according to instructions has been shown to be an independent predictor of high-quality preparation (6). Measures to enhance compliance, such as education of the medical staff administering the bowel preparation, have not been shown to improve the quality of the preparation (6). The majority of patients with inadequate bowel preparation undergo an incomplete colonoscopy. Improvement in the quality of preparation would enhance colonoscopy completion rates (2), theoretically increase diagnostic yield and limit the requirements for repeat procedures.

In the present study, we sought to determine the effect of patient education on the adequacy of bowel preparation for colonoscopy. We hypothesized that by giving patients a brief counselling session followed by standardized, written instructions outlining the bowel preparation and its purpose, we could improve the bowel preparation of inpatients.

\footnotetext{
${ }^{1}$ Division of Gastroenterology, Department of Medicine, University of British Columbia; ${ }^{2}$ St Paul's Hospital, Vancouver, British Columbia Correspondence: Dr Greg Rosenfeld, Department of Medicine, University of British Columbia, 770-1190 Hornby Street, Vancouver,

British Columbia V6Z 2K5. Telephone 604-329-9552, fax 604-689-2004, e-mail grosenfeld@telus.net

Received for publication November 19, 2009. Accepted January 22, 2010
} 


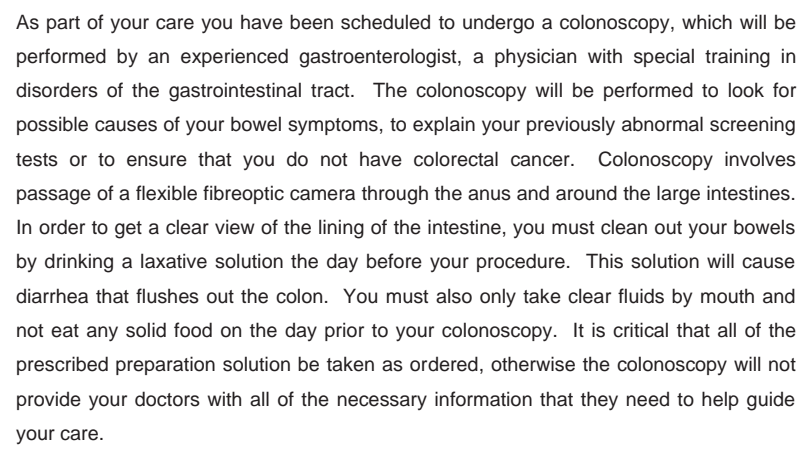

The colonoscopy will be performed at the St. Paul's Hospital Gastroenterology clinic

The colonoscopy usually takes 20-40 minutes to complete and is followed by approximately 1 hour of recovery time during which sedatives and painkillers wear off. If any polyps are found, they will be removed during the procedure and sent for analysis by a pathologist at St. Paul's Hospital. After the colonoscopy, a trained nurse will monitor you in the recovery area until you are ready to safely leave the hospital.

Figure 1) Information sheet given to patients undergoing colonoscopy at St Paul's Hospital (Vancouver British Columbia). GoLYTELY (Braintree Laboratories, USA)

\section{Patients}

\section{METHODS}

The study participants were patients who were referred for colonoscopy to the gastroenterology service at St Paul's Hospital (a tertiary care general hospital in Vancouver, British Columbia) between August and December 2008. To be included in the study, patients were required to be older than 19 years of age, willing to participate, and able to understand and follow written instructions in English. The patients could have any indication for colonoscopy and were assigned to either the standard preparation group or the enhanced instruction group according to when they were enrolled in the study. The study was conducted over approximately 16 weeks. For the first eight weeks, all of the enrolled subjects were assigned to the standard preparation group; then, during the final eight weeks, all of the enrolled subjects were assigned to the intervention group. Standard preparation included $4 \mathrm{~L}$ of a commercially available bowel preparation (GoLYTELY, Braintree Laboratories, USA) given orally with a clear liquid diet on the day before colonoscopy along with routine instructions regarding the bowel preparation and procedure. The enhanced instruction group received the same colonic preparation; however, in addition, they received a brief 5 min counselling session to discuss the importance of the bowel preparation and how it should be taken. Written information was left with the patient to reinforce the key points (Figure 1).

\section{Protocol}

Standard orders consisting of instructions to give the patient a clear liquid diet for $24 \mathrm{~h}$ before colonoscopy, withhold oral food and fluids after midnight on the day of the procedure, and to

\section{TABLE 1}

\section{Cleanliness quality score}

\begin{tabular}{ll}
\hline Score & Description \\
\hline 0 & Dry colon with no solid feces \\
1 & Only transparent fluid \\
2 & Liquid stool \\
3 & Small amount of solid feces with $\geq 90 \%$ of the mucosa visible \\
4 & Solid feces with $<90 \%$ of the mucosa visible \\
\hline
\end{tabular}

Adapted from reference 7

have the patient consume $4 \mathrm{~L}$ of GoLYTELY over a span of $4 \mathrm{~h}$ to $6 \mathrm{~h}$ starting at approximately 12:00 the day before the procedure were written in the patients' charts. The control patients were told that they were to undergo a colonoscopy and that they would need to take a laxative solution the day before in preparation. The intervention group patients were told the same; however, they also received a 5 min talk explaining that the preparation allows for proper visualization of any abnormalities and that it should be taken in the afternoon on the day before the test. They were instructed not to eat solid food for $24 \mathrm{~h}$ before the test and were informed of the importance of consuming as much of the preparation as possible to allow for good visualization at colonoscopy. The gastroenterology residents used the written materials as a guide but did not necessarily strictly read the instructions to the patient. Patients were given the opportunity to have their questions answered at the end of the counselling session. The gastroenterology resident provided the counselling session at the bedside where the written instructions were reviewed and left with the patient. The nursing staff was not given any specific instructions with respect to either group beyond the written orders in the patient chart nor were they made aware of the study group to which the patient belonged. They were left to provide their 'usual care', which does not include giving patients instruction as to how to take the preparation or an explanation as to its importance. The patient's family was not involved in the counselling and played no role in the study.

At the time of colonoscopy, the quality of bowel preparation was assessed using a standardized scoring system as previously described (7) (Table 1). Patients were assigned a score from 0 to 4 , ranging from a dry colon with no solid feces seen (score $=0$ ) to the presence of solid feces with less than $90 \%$ of the colonic mucosa visible ( assigned by the physician performing the colonoscopy who was blinded to the preparation instructions given.

\section{Data analysis}

A Mann-Whitney $U$ test was performed on the bowel cleanliness scores to compare the two groups. Furthermore, the two groups were also compared in terms of demographics, the indication for colonoscopy and the findings at colonoscopy.

The primary end point of the present study was the mean score of bowel cleanliness in the two groups. Based on this objective, the sample size was calculated. Assuming the educated group would have an improvement of their score by one point with a common SD of $0.25,16$ patients would be necessary in both groups to have a power of $80 \%$ using a two-sided $t$ test with $\mathrm{P} \leq 0.05$ considered to be statistically significant. 


\section{RESULTS}

In total, 38 patients were enrolled, with 22 in the standard preparation group and 16 in the enhanced-instruction group. In the standard preparation group, 16 patients (73\%) were men and six patients $(27 \%)$ were women, compared with the enhanced instruction group in which 13 were men $(81 \%)$ and three were women (19\%). The average age of the standard preparation group was 67.9 years, and 65.1 years for the intervention group. The indications for referral in the standard preparation and the enhanced education intervention groups, respectively, were as follows: hematochezia (55\%, 31\%), a mass seen on computed tomography examination (5\%, 31\%), irondeficiency anemia $(14 \%, 19 \%)$, abdominal pain $(9 \%, 0 \%)$, diarrhea $(14 \%, 5 \%)$, Streptococcus bovis bacteremia (5\%, 0\%), occult bleeding $(0 \%, 6 \%)$ and melena $(0 \%, 6 \%)$. The findings at colonoscopy for the standard preparation and the enhanced instruction intervention groups, respectively, were as follows: the presence of polyps $(36 \%, 19 \%)$, diverticuli $(27 \%, 19 \%)$, a normal examination $(9 \%, 25 \%)$, a colonic mass $(9 \%, 19 \%)$, inflammatory changes $(9 \%, 12 \%)$ or hemorrhoids $(5 \%, 0 \%)$.

The bowel preparation scores ranged from 0 to 4 in both groups. For the control group, one patient scored 0 , one scored 1 , five scored 2, 14 scored 3 and one patient scored 4 (Figure 2). In the enhanced instruction group, three patients scored 0 , four scored 1 , seven scored 2, one scored 3 and one patient scored 4 (Figure 2). The median bowel preparation scores were 3.0 in the control group and 2.0 in the enhanced instruction group - a result that was statistically significant $(P=0.001)$ using the MannWhitney U test.

\section{DISCUSSION}

Hospitalized patients are not as well prepared for colonoscopy as ambulatory outpatients (8). Inadequate bowel preparation is a common cause of poor quality colonoscopy, resulting in prolonged procedure times and failure to detect pathology (3). As a result of failed colonoscopy, some patients undergo repeat procedures or computed tomography colonography. This is associated with a significantly increased cost $(1,9)$ and risk to the patient. A microcosting approach to colonoscopy in Canada (10) has shown that the cost of an individual colonoscopy ranged from $\$ 352$ for a diagnostic colonoscopy to $\$ 467$ for a therapeutic endoscopy. These numbers did not take into account the added costs of an inpatient stay, which may be prolonged because of a failed colonoscopy. If we consider these costs, plus the additional costs of repeat colonoscopy, then any intervention that improves bowel preparation, thereby alleviating the need for repeat procedures and reducing the duration of hospital stay, should be highly favourable in a cost-benefit analysis. We believe that patient education in the form of written instructions and counselling is one such intervention.

The present study showed that the quality of inpatient bowel preparation could be improved by providing a short counselling session and administering a standard set of written instructions regarding the preparation. The two groups in the current study were similar with respect to indication for colonoscopy and the findings observed at colonoscopy, suggesting that the instructions represent an independent variable on the quality of bowel preparation. Several other studies $(1,4,6)$ have investigated the impact of other variables such as the cleansing agent, the timing of administration or the regimen on the adequacy of

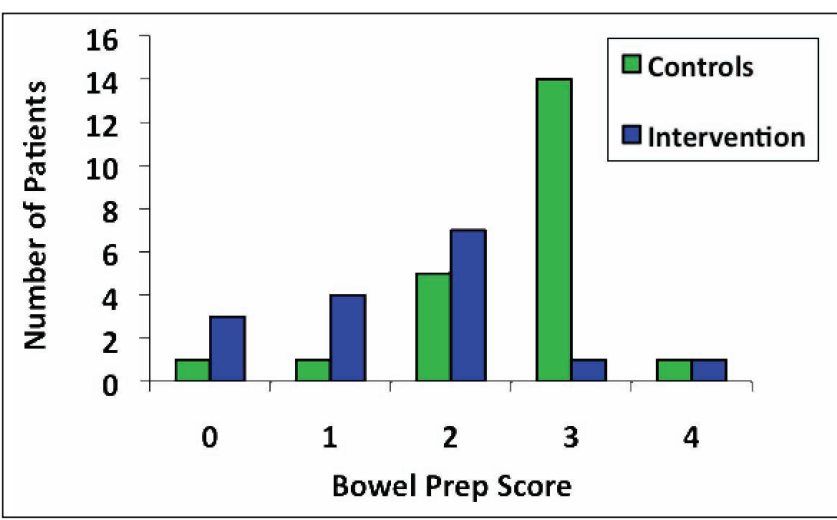

Figure 2) Chart showing the number of patients who were assigned a given bowel preparation (Prep) score in each group. A score of 0 is the best possible preparation allowing the most visibility, while a score of 4 represents the poorest preparation

bowel preparation for colonoscopy. However, few studies have investigated these variables for hospital inpatients. Previously, the implementation of an education program for medical staff was not shown to improve preparation quality or colonoscopy success (6). However, to date, the present study was the first to demonstrate the impact of patient education on the quality of bowel preparation for inpatients. This may be because in this setting, the patient is empowered to manage their own preparation rather than depending on the nursing staff.

There were several limitations in the current study. First, the present study only recruited patients who could read English, which limits the generalizability of these results because individuals who cannot read English may have other issues surrounding their colonoscopy preparation that may not be accounted for by this education intervention. Second, the subjects were not truly randomized because they were assigned based on timing of enrollment, with all of the standard preparation group being enrolled consecutively followed by the enhanced instruction group, which may have introduced an unidentified bias. Third, because of the small sample size, other variables that are known to impact the quality of the preparation could not be controlled for. This may have included the 'usual care' practice of the nursing staff, which we would expect to be the same for both groups but, nevertheless, remains a potential source of bias. Fourth, the nature of a patient's illness or comorbidities may result in cognitive impairment that could affect the ability to understand the bowel preparation instructions - the two groups in the present study were not matched for the presence of comorbid conditions. Fifth, the use of our intervention with other colonic preparations that may have similar results and are better tolerated (eg, sodium phosphate preparations, Pico-Salax [Ferring Pharmaceuticals, USA] or magnesium citrate $[1,11]$ ) than GoLYTELY may not have produced the same results. However, because sodium phosphate laxatives have the potential to cause serious or even fatal electrolyte shifts, and are potentially nephrotoxic in elderly patients or those with renal insufficiency (12), GoLYTELY is our standard preparation for in-hospital colonoscopies. Finally, due to the small sample size, no attempt was made to correlate whether the improved bowel preparation resulted in a higher diagnostic yield for colonoscopy as previously suggested by others (13). Nevertheless, based on the work of others $(2,9)$, 
we would expect higher completion rates and decreased costs to be associated with better bowel preparation. Patient counselling and education regarding bowel preparation procedures and the importance of adequate preparation positively impacts the quality of bowel preparation for inpatient colonoscopy. Patient counselling and written instructions are inexpensive, safe and simple interventions, and are an effective means to optimize the diagnostic yield of colonoscopy in the inpatient setting. The results of the present study suggest that incorporation of patient education into the bowel preparation regimen would help to improve the overall adequacy of bowel preparation for hospital inpatients.

\section{REFERENCES}

1. Barkun ACN, Enns RMM, Natsheh SPC, Sadowski DVS. Commonly used preparations for colonoscopy: Efficacy, tolerability and safety: A Canadian Association of Gastroenterology position paper. Can J Gastroenterol 2006;20:699-712.

2. Hendry PO, Jenkins JT, Diament RH. The impact of poor bowel preparation on colonoscopy: A prospective single centre study of 10,571 colonoscopies. Colorectal Dis 2007;9:745-8.

3. Harewood GC, Sharma VK, de Garmo P. Impact of colonoscopy preparation quality on detection of suspected colonic neoplasia. Gastrointest Endosc 2003;58:76-9.

4. Ness RM, Manam R, Hoen H, Chalasani N. Predictors of inadequate bowel preparation for colonoscopy. Am J Gastroenterol 2001;96:1797-802.
5. Reilly T, Walker G. Reasons for poor colonic preparation with inpatients. Gastroenterol Nursing 2004;27:115.

6. Chorev N, Chadad B, Segal N, et al. Preparation for colonoscopy in hospitalized patients. Dig Dis Sci 2007;52:835-9.

7. Vanner S, MacDonald P, Paterson W, Prentice R, Da Costa L, Beck I. A randomized prospective trial comparing oral sodium phosphate with standard polyethylene glycol-based lavage solution (Golytely) in the preparation of patients for colonoscopy. Am J Gastroenterol 1990;85:422-7.

8. Borkje B, Pedersen R, Lund GM, Enehaug JS, Berstad A. Effectiveness and acceptability of three bowel cleansing regimens. Scand J Gastroenterol 1991;26:162-6.

9. Rex DK, Imperiale TF, Latinovich DR, Bratcher LL. Impact of bowel preparation on efficiency and cost of colonoscopy. Am J Gastroenterol 2002;97:1696-700.

10. Sharara N, Adam V, Crott R, Barkun AN. The costs of colonoscopy in a Canadian hospital using a microcosting approach. Can J Gastroenterol 2008;22:565.

11. Parente F, Marino B, Crosta C. Bowel preparation before colonoscopy in the era of mass screening for colo-rectal cancer: A practical approach. Dig Liver Dis 2009;41:87-95.

12. Wexner SD, Force T, Beck DE, et al. A consensus document on bowel preparation before colonoscopy: Prepared by a task force from the American Society of Colon and Rectal Surgeons (ASCRS), the American Society for Gastrointestinal Endoscopy (ASGE), and the Society of American Gastrointestinal and Endoscopic Surgeons (SAGES). Gastrointest Endosc 2006;63:894-909. (Erratum in 2006;64:154).

13. Mitchell RM, McCallion K, Gardiner KR, Watson RG, Collins JS. Successful colonoscopy: Completion rates and reasons for incompletion. Ulster Med J 2002;71:34-7. 


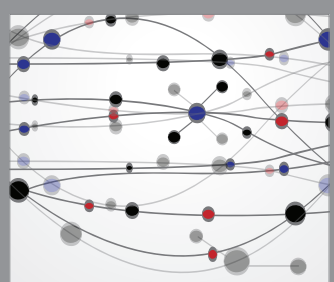

The Scientific World Journal
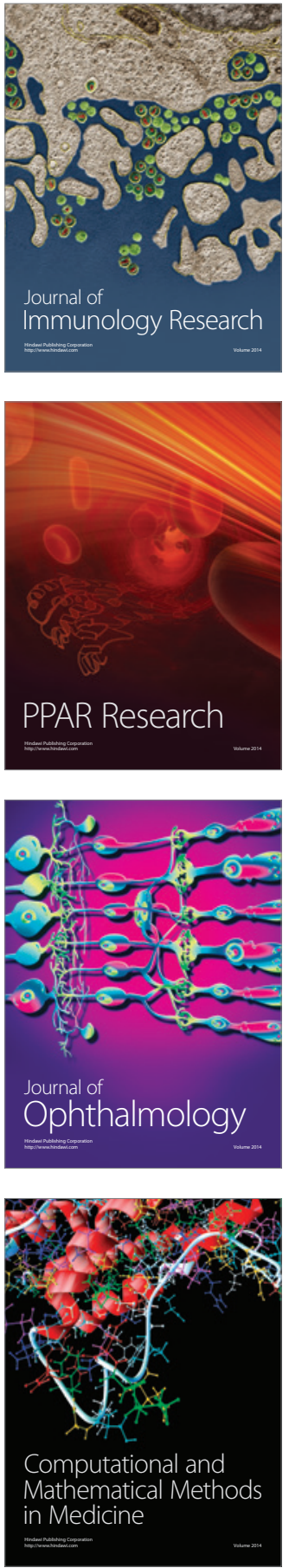

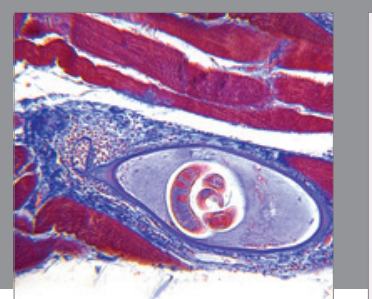

Gastroenterology Research and Practice

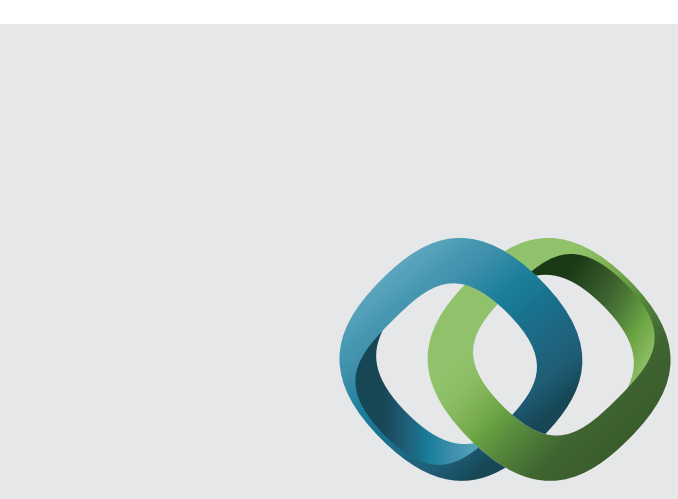

\section{Hindawi}

Submit your manuscripts at

http://www.hindawi.com
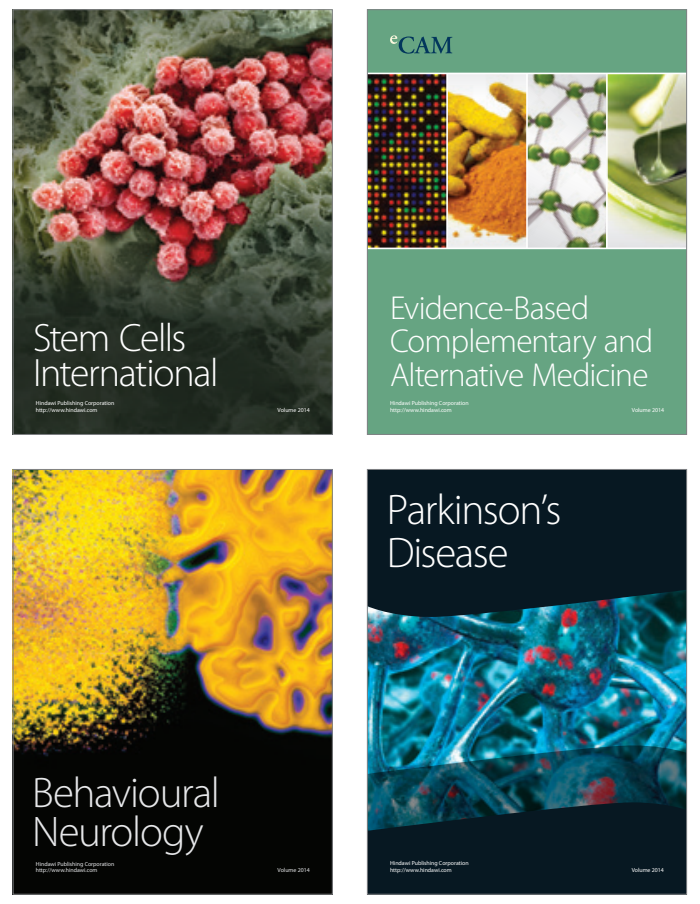
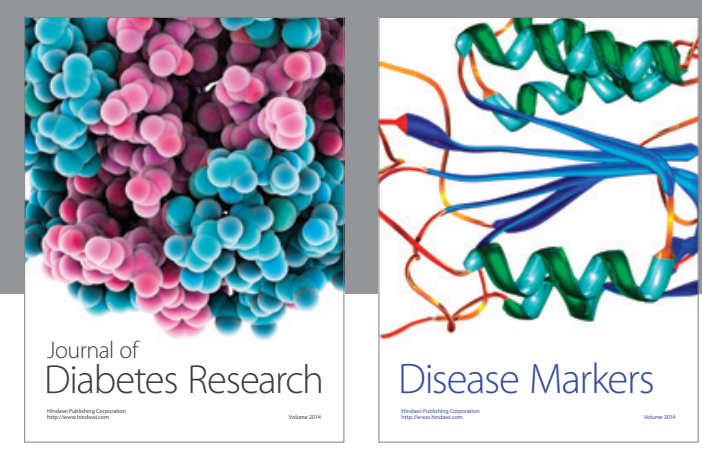

Disease Markers
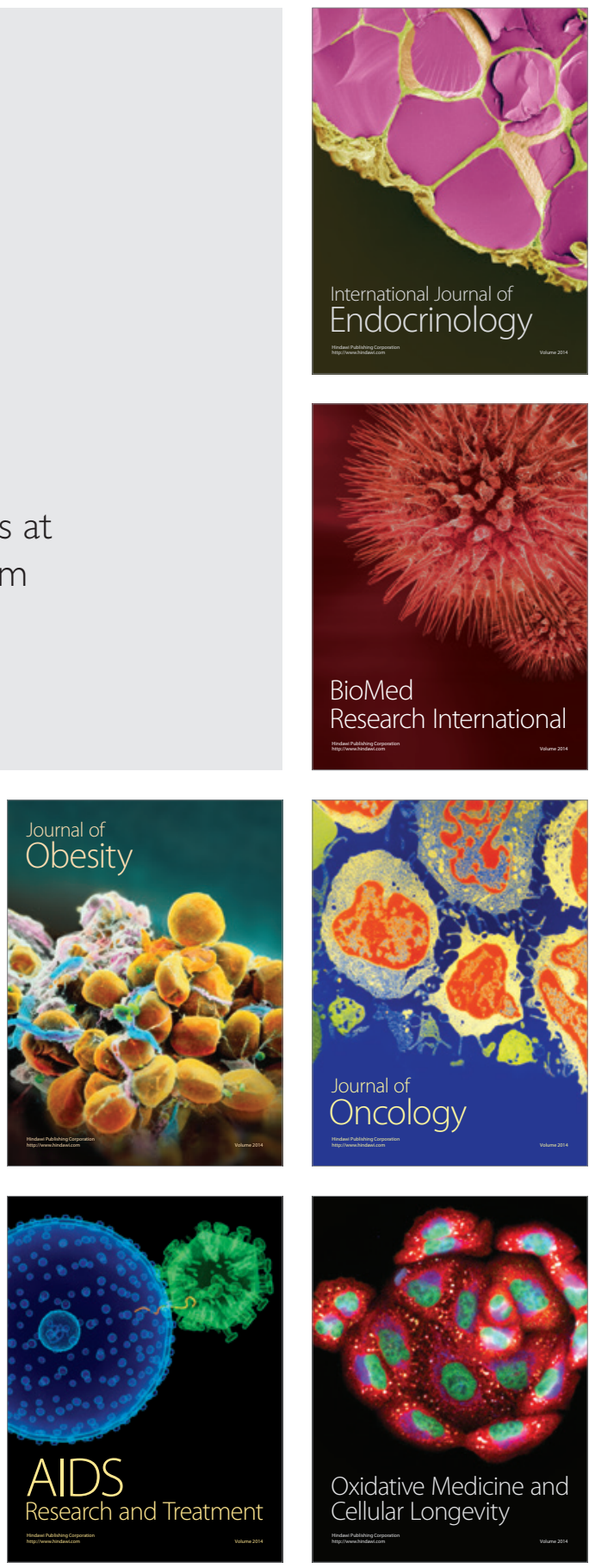